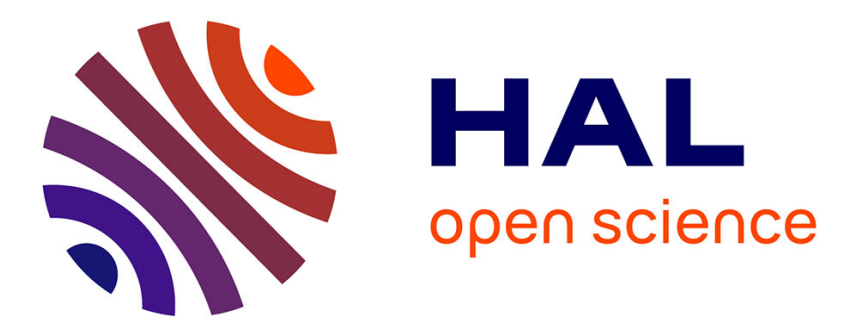

\title{
System approach to the pre-design of electric propulsion systems for road vehicles
}

Moncef Hammadi, Maurizio Iebba, Felipe Camargo Rosa, Ottorino Veneri, Clemente Capasso, Stanislao Patalano, Giovanni Copertino

\section{- To cite this version:}

Moncef Hammadi, Maurizio Iebba, Felipe Camargo Rosa, Ottorino Veneri, Clemente Capasso, et al.. System approach to the pre-design of electric propulsion systems for road vehicles. Systems Engineering (ISSE), 2015 IEEE International Symposium, Sep 2015, Rome, Italy. 10.1109/SysEng.2015.7302762 . hal-01322919

\section{HAL Id: hal-01322919 https://hal.science/hal-01322919}

Submitted on 28 May 2016

HAL is a multi-disciplinary open access archive for the deposit and dissemination of scientific research documents, whether they are published or not. The documents may come from teaching and research institutions in France or abroad, or from public or private research centers.
L'archive ouverte pluridisciplinaire HAL, est destinée au dépôt et à la diffusion de documents scientifiques de niveau recherche, publiés ou non, émanant des établissements d'enseignement et de recherche français ou étrangers, des laboratoires publics ou privés. 


\section{System Approach to the Pre-Design of Electric Propulsion Systems for Road Vehicles}

\author{
Moncef HAMMADI and Maurizio IEBBA \\ Institut Supérieur de Mécanique de Paris \\ Saint-Ouen, France \\ moncef.hammadi@supmeca.fr \\ maurizio.iebba@hotmail.it \\ Felipe CAMARGO ROSA \\ CAPES Foundation, Ministry of Education of Brazil \\ Brasilia - DF, Zip Code 70.040-020 \\ felipecamargo36@gmail.com
}

\author{
Ottorino VENERI and Clemente CAPASSO \\ CNR - National Research Council of Italy - Istituto Motori \\ Naples, Italy \\ o.veneri@im.cnr.it \\ c.capasso@im.cnr.it
}

\author{
Stanislao PATALANO and Giovanni COPERTINO \\ Università degli Studi di Napoli Federico II, \\ stanislao.patalano@unina.it \\ giovannicopertino@gmail.com
}

\begin{abstract}
The current critical environmental context has increased the interest in electric vehicles. However, the evaluation of which one is the best choice, for the electric vehicle components, generally requires a series of experimental tests to be carried out, which can be quite costly and not as adequate as an engineering project must be. Therefore, this paper presents an approach, based on the RFLP method, which can help the designer, during the pre-design of an electric propulsion system, to choose the best configuration for the components of an electric vehicle power-train, reducing the costs related to physical experimentation on a laboratory test benches or on a real electric vehicle. The aim of this paper is to provide a computational tool that could virtually simulate the behavior of a designed electric propulsion system facilitating the solution of the most common problems encountered on the domain of battery-powered vehicles. The case study considered in this work is power-train for an electric scooter. The first step of this work consists in defining simulation models to simulate the power-train in terms of vehicle performance and energetic consumption. In the second step, those models are parameterized and validated through experimentations on a physical electric power-train installed in a laboratory of Istituto Motori (National Research Council of Italy). The validation of the evaluated models allows to carry out simulation tests on different alternative configurations of the electric power-train in the most varied drive conditions. At the end, the proposed model of the whole power-train system is used to carry out a study for the right design of the battery pack.
\end{abstract}

Keywords - Dymola; ModelCenter ${ }^{\circledR}$; Electric Vehicle; Testbench; Battery; Systems Engineering; RFLP method; Electric Motor

\section{INTRODUCTION}

During the last decades, a growing concern over the problems associated with hydrocarbon fueled vehicles as well as the sustainability of the current worldwide hydrocarbonbased transport has emerged [1]. As a consequence, the interest in propulsion systems for road transport alternative to the actual petroleum-based has increased. One of the most promising ways to reduce the dependency from fossil fuel is the electrification of road transport systems [2], but this process is still in its outset, because of many factors that reduce market penetration of electric vehicles. A key aspect to increase the diffusion of electric vehicles is the reduction of purchase cost [3]. A remarkable contribution to this aim is the optimization of the design process of the vehicle with all its subsystems.

A powertrain for an electric vehicle can be considered a mechatronic system [4], since its design involves a close interaction between mechanics, electricity, electronics, and control theory. Consequently, the design of an optimal powertrain for a certain application is a challenge that requires engineers to operate in the context of Systems Engineering (SE). SE is an interdisciplinary approach to the design that focuses on how to design and manage complex systems over their life cycles [5]. SE coordinates all the interdisciplinary tasks, which are required throughout a system life cycle to transform customer needs, requirements, and constraints into a system solution. SE establishes the principles of all the activities necessary to manage product development, ensuring that the product is properly designed, affordable to produce, operate, maintain, and eventually to dispose of.

In the present work, the preliminary design of an electric power-train for a scooter is carried out by means of RFLP, a method proper of SE that allows to deal with the engineering of a complex system. Such method is based on well-known "V-model" [6] and has the advantage to be implemented in CATIA platform.

\section{Project Context AND OBJective}

The present work was carried out in the context of the international research program PLACIS (in French, "Plateforme Collaborative d'Ingénierie Systèmes"). This program allowed to carry out the study described in the present paper through a partnership between the engineering school Institut Supérieur de Mécanique de Paris (Supméca) the University of Naples Federico II and CNR - National Research Council of Italy - Istituto Motori.

The collaborative platform of PLACIS permitted to deal with the multidisciplinary problem of designing an electric power-train facilitating the collaboration of engineers located 
in different countries. This is a recurrent situation in the context of SE, because the complexity of actual products requires several engineers, with different specialisation, working together on different aspect of a project in a coordinated way.

The aim of this collaborative project was to provide, in Dymola environment, a Modelica library containing the components of an electric power-train. The created library can facilitate the transition between logical and physical modelling levels according to the RFLP approach and also can check the behaviour of a real electric vehicle during its pre-design.

\section{RFLP APPROACH}

RFLP approach is a methodology that supports engineers to design complex engineering systems within the interdisciplinary field of SE [7]. It allows the designers to manage the workflow from requirement analysis to physical design in order to reduce the lead-time and consequently the costs of the system under study [8].

The acronym RFLP synthetizes the four levels on which the approach works: Requirements engineering, Functional analysis, Logical design and Physical design. As a matter of fact, RFLP consists on a systematic approach that enables an engineering project to evolve from a system analysis to a system design and implementation [8]. In that way, as a project usually faces many issues throughout its development, such as reliability, maintainability, logistics, evaluation and optimization.

This approach allows different disciplines to be integrated and be managed in an appropriate manner, respecting all the relations and aspects described by the V-model, Fig. 1 .

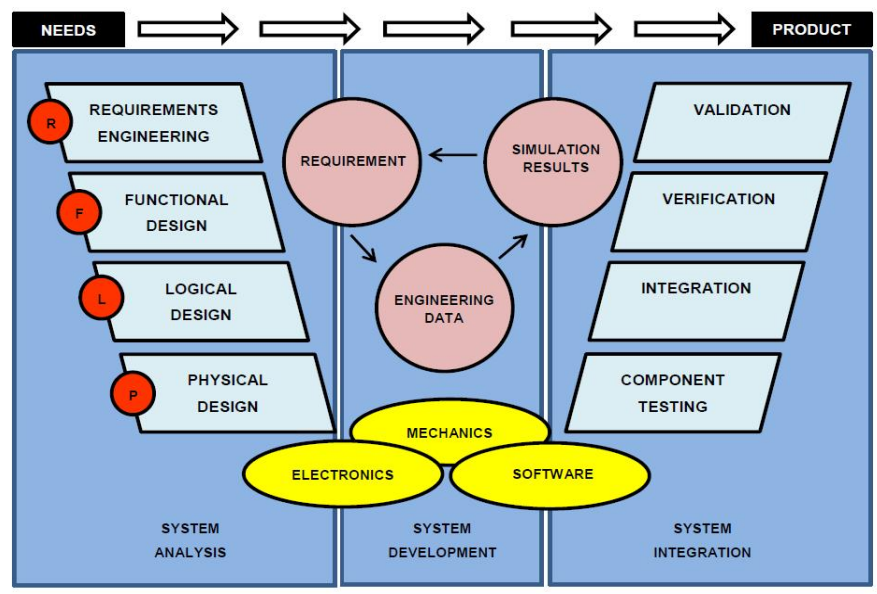

Fig. 1. V-Model of Systems Engineering

Although this approach is at the basis of the present work, its use has been focused to the last two levels of design (Logical and Physical), because, using Dymola modeling environment, these are the only two levels to be studied. In other words, this choice is due to the usual constrains present on studies performed on physical domain, which does not allow an engineer to verify the relation between the parameters contained on electrical components datasheets and their real behavior and performance.

Thereby, a good computational model should integrate both the physical and logical domains, so that the adequate connection of the two levels can ensure the validity of the model and can provide accurate results for the pre-design process.

\section{DYMOLA POWER-TRAIN MODEL}

The creation of computational electric vehicle power-train was performed on the Dymola modeling environment.

The developed model is composed of both original blocks, contained in Modelica library, and new ones designed according to the fundamental equations that rule the behavior of the considered electrical vehicles components.

As shown on Fig. 2, the created Dymola model is composed of six main parts:

- Battery Pack;

- Inverter $\mathrm{DC} / \mathrm{AC}$;

- Electric Synchronous Motor;

- Control System;

- Mechanical Transmission;

- Resistive Forces.

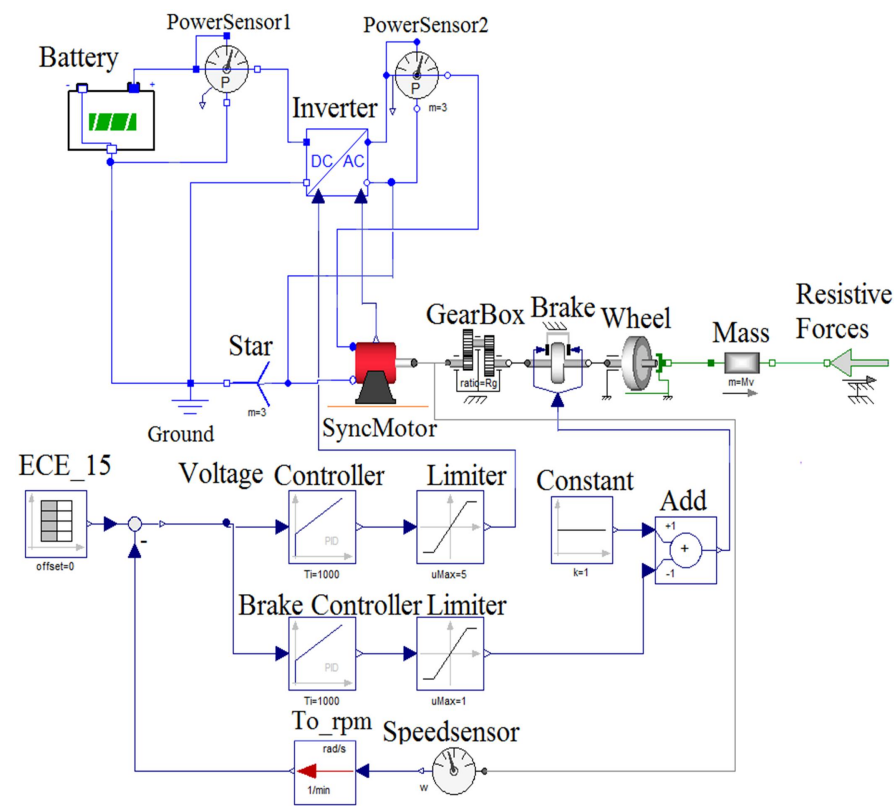

Fig. 2. Dymola Test bench model model, implemented in Dymola.

\section{A. Battery Pack}

Generally battery modelling is a complex task since all the main parameters that influence the battery properties (State Of Charge, voltage, current, temperature) are dynamically 
correlated to each other in a highly non-linear way. In this work a physical model of a battery is obtained by considering a static equivalent circuit of the system represented by an ideal open-circuit voltage source in series with a resistor that represents the internal resistance of the battery [10].

The Dymola Battery model, specifically developed for this work (Fig. 3), has a characteristic cyclical behavior, in which each iteration of the simulation considers the effect of discharge using the parameters of the previous iteration.

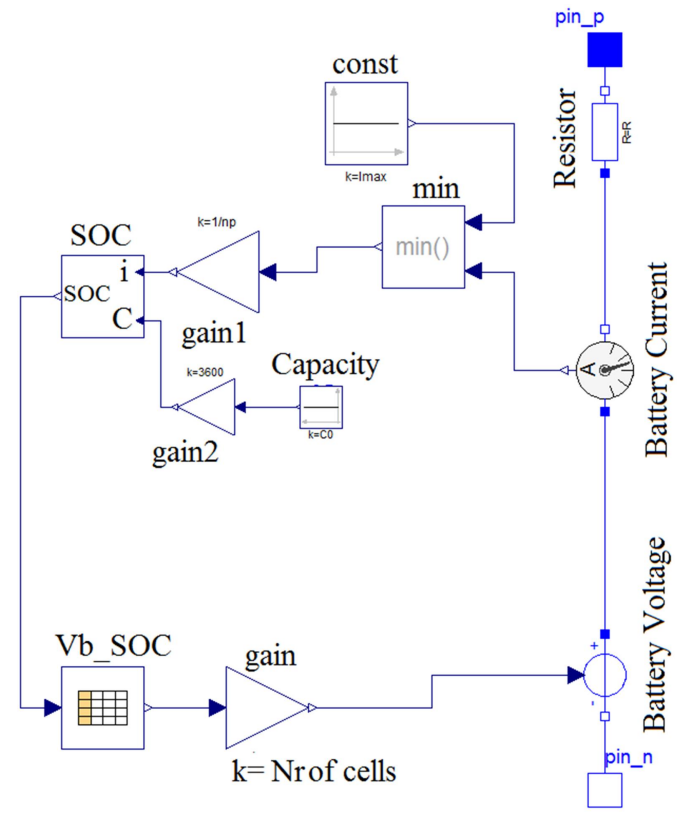

Fig. 3 Dymola Battery model.

In a detailed way, once the capacity $\mathrm{C}$ of the battery pack is fixed, for each iteration the model, measuring the instant current $\mathrm{I}(\mathrm{t})$ of the battery, is able to calculate the SOC (State of Charge), as shown on (1). This value is inserted as input on a look-up table that represents the dependence of SOC to battery cell voltage.

$$
S O C=\int_{t_{0}}^{t} I(t) C d t
$$

After that, the model calculates the instant voltage, that the battery pack is capable to provide to the system at a certain moment, multiplying the value, obtained from the table, for the number of the battery cells in series.

\section{B. Inverter}

In the case of the Inverter, the developed model is based on a computational code that performs the conversion from DC current to AC current, respecting the balance between the electrical power in input, which comes from the Battery, and the electrical power in output, which will be delivered to the AC Motor. Equations (2), (3) and (4) are applied to ensure those conditions.

$$
V=a \frac{\sqrt{3}}{\sqrt{2}} V \sin \left(w_{E} t\right)
$$

$$
\begin{gathered}
P_{R}=V i \\
\eta P_{B}=P_{R}
\end{gathered}
$$

In the former equations, $a$ is the parameter that connects the Inverter to the Control System, allowing the latter to amplify or reduce the three-phase voltage magnitude $V, P_{B}$ is the electric power in output from the Battery Pack and $P_{R}$ is the electric power in output of the Inverter.

On the other hand, the inverter electric pulsation $w_{E}$ derives from the motor shaft angular speed equation, given by(5). This relation characterize the connection between the Inverter and the Electric Motor, and it also represents the capability of the Inverter to change the shape of the signal waves of voltage according to the engine demand of torque.

$$
w_{E}=p \quad w_{M}
$$

where $p$ is the number of the pole pairs of the Motor and $w_{M}$ is the mechanical angular speed of the Motor shaft.

It is important to underline that any changes on the values of the current and voltage, performed by the inverter, have a direct influence on the magnitude of torque and speed rotation of the engine. This statement can be simply verified by the presence of the variable $w_{E}$ on (2) and (5), which in some way are linked to the electrical and mechanical behavior of inverter and engine, respectively.

\section{Synchronous Electric Motor}

The electric motor block represent the transition between the electrical and mechanical levels. As a matter of fact its role is to convert the electrical power which flows from the inverter into mechanical power in output of its shaft.

In order to adapt the model to its specific application, the designer has to define some parameters: nominal and maximum values of the power, max speed rotation and max torque. For this reason the created Dymola model is very flexible and can be adapted to any application.

There are also other six more variables that define the designed model. These variables simulate the behavior of the internal components of the engine. As a matter of fact, the Dymola model of the motor is based on an electrical circuit that is composed of a resistor, an inductor and a mutual inductance that are supplied by the electrical power coming from the inverter.

The model of the Motor is based on the following equation:

$$
V=R i(t)+L \frac{d i(t)}{d t}+M \frac{d i(t)}{d t}+E
$$

where $R$ is the resistance, $L$ is the inductance and $M$ is the constant of mutual inductance of the equivalent electric scheme for the used electric motor [11]. 
This expression is used by the Dymola model in order to calculate the value of the electromagnetic force $E$ defined as follows:

$$
E=\frac{\varphi_{F}}{p} w_{E} \sin \left(w_{E} t\right)
$$

Then, as the equation (8) shows, $E$ is used by the simulation in order to determine the percentage of the electrical power that will be converted into mechanical power by the electric motor.

$$
P_{E}=E i
$$

Finally, once the calculation of electric power $P_{E}$ is done, the model is able to calculate the values of the two output parameters of the engine: the torque $C$ and the shaft speed rotation $w_{M}$. (9):

$C$ is obtained by the division between $P_{E}$ and $w_{M}$ equation

$$
C=\frac{P_{E}}{w_{M}}
$$

However, in order to respect the constraints of the machine, the result of (9) is compared by the software to the maximum torque already set by the designer. Thus, the minimum value between them is taken into account and attributed to C. This is also valid for the value of $w$. Its value is obtained choosing the minimum value between the motor maximum speed rotation and the derivative of the shaft angle.

\section{Control System}

The role of this component is to ensure that the reference speed of a certain driving cycle is followed, by the vehicle, during the simulation. The Control System is capable to achieve this goal changing the values of some parameters that have a major influence over the performance of the designed electric vehicle.

In the developed Dymola model, the Control System accepts two inputs (speed reference and test bench speed feedback) and two output control parameters (inverter voltage control coefficient and braking control coefficient). The block scheme of this component is shown in Fig. 4.

The designed system works as follows: at first, the block feedback calculates the difference between the input speed reference and the current angular velocity of the motor shaft in order to send the result to the Voltage_Controller and the Brake_Controller. These two PID controllers are responsible to rea $\bar{d}$ and evaluate the response of feedback in order to give the most appropriate values for the output parameters, according to their own control characteristics.

Nevertheless, if those outputs are not limited, the Control System may become instable. This is the reason why there are two other blocks whose function is to limit the output of the PID controllers (Voltage_Limiter and Brake_Limiter).

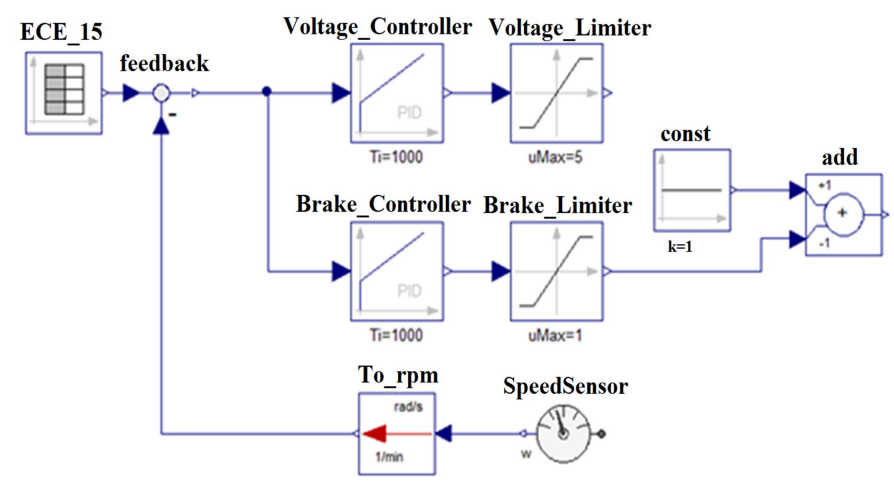

Fig. 4. Model of Control System

The constraint intervals of the limiters are defined on the two following expressions:

$$
\begin{gathered}
0<\text { Voltage_Limiter. } y<5 \\
0<\text { Brake_Limiter } y<1
\end{gathered}
$$

Thereby, the control commands will be inserted on the Inverter and on the Brake as the parameters $a$ and $f$, respectively. This last variable represents the brake force normalized and it is explained in the brake section.

The variable Voltage_Limiter.y, enables the Inverter to work as a transformer $\mathrm{AC} / \mathrm{AC}$, either amplifying or reducing the magnitude of the three-phase voltage that supplies the electric motor. As a matter of fact, using the maximum value of 5 for $a$, the Motor is able to reach high reference speeds required by the driving cycle.

Even if the value of the voltage amplitude is modified by the control system, the balance between the power in input and output of the Inverter is respected, because while the amplitude of the voltage is increased, at the same time the current amplitude is reduced in the same proportion.

\section{E. Transmission System}

The Transmission system is composed of four Dymola blocks: a gear box, a brake, a wheel and a mass. For each different vehicle, there are distinct values of the parameters that define those components. Thereby, the designer must specify all the characteristics of the transmission system before launching the simulation.

First of all, inside the gear box block, there is only one parameter that should be considered, which is the ratio of transmission $R_{G}$. For this approach, its value was considered to be constant in order to avoid some problems of discontinuities on the Dymola environment.

Furthermore, the presence of the brake in the test bench model was taken into consideration due to the necessity of decelerating the vehicle when the driving cycle requires sudden drops in speed. Equation (12) shows the relation between the applied braking force and the braking control signal $f$ which flows from the control system.

$$
F_{N}=F_{M A X} f
$$


The last two components (wheel and mass) represent the transition from the rotational movement of the electric motor shaft to the translational movement of the vehicle. Moreover, they were modeled in such a way that they could simulate the effect of the mass of the vehicle over its wheels.

\section{F. Resistive Forces}

During a driving test, a vehicle is subjected to various resistive forces. The most notable of them are: the aerodynamic drag, the rolling resistance and the road slope resistance.

The model considered to estimate the resistances on vehicle, is based on the well-known longitudinal dynamics. It considers a single rigid body driving straight ahead on a plane road.

In order to apply the effect of those forces on the electric vehicle model, it was created a block that calculates the total resistant force imposed to the vehicle, according to the expression (13).

$$
R_{F}=0,5 C_{D} \rho A V_{v}^{2}+C_{R} M_{V} g \cos (\alpha)+M_{V} g \sin (\alpha)
$$

$C_{D}$ is the coefficient of aerodynamic drag, $\rho$ is the air density, $A$ is the frontal area of the vehicle, $\mathrm{C}_{\mathrm{R}}$ is the coefficient of rolling resistance between the ground and the wheels and $\alpha$ is the slope of the road.

\section{THE VALIDATION OF THE POWER-TRAIN MODEL}

In order to validate the model, there were taken into consideration experimental data of a Scooter laboratory test bench, designed by Istituto Motori [9]. That information would establish the criteria to determine if the model had a good performance or not.

The validation process was structured as follows:

- Adaptation of the model according to the Scooter specifications;

- Insertion of the experimental reference data and the european driving ECE-15 (UDC - Urban Driving Cycle (Fig.5);

- Acquisition of the optimization results and final data comparison.

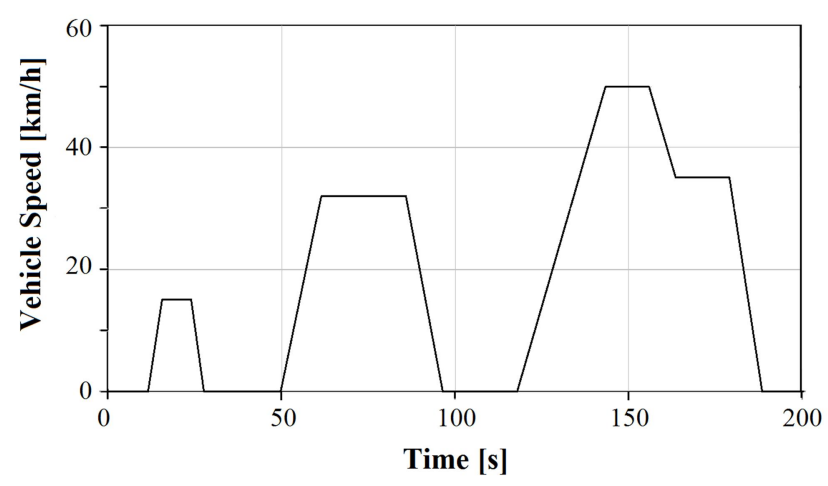

Fig 5. Driving Cycle ECE-15
The objective was to find a match between the curves of battery performance obtained through the simulation and the real ones experimentally measured by Istituto Motori. Thereby, the laboratory data were inserted in the Dymola model as reference blocks in order to compare the different behavior of the two curves along the simulations.

In fact, the curves of voltage, current and state of charge of the Battery Pack were chosen as parameters of comparison due to the fact that they can provide useful data about the performance of the whole designed electric propulsion system. Moreover, the reference data [9] were collected during practical studies focused on the battery pack of a scooter power-train.

Therefore, as it can be seen on Fig. 6, a first comparison between the simulation and reference curves of battery current showed a not good match between the simulation and the real results.

In order to obtain a match of the curves, it was used the software ModelCenter ${ }^{\circledR}$, which enables users to conduct trade studies, as well as optimize designs. At first, a preliminary study of the model showed that the values of the gear ratio $R_{G}$, internal resistance of the battery $R_{B}$ and electromagnetic constant of the motor $\varphi_{F}$ had a considerable influence on the behavior of the simulation curves of the battery voltage and current. For these reason these parameters were chosen as variable in ModelCenter ${ }^{\circledR}$.

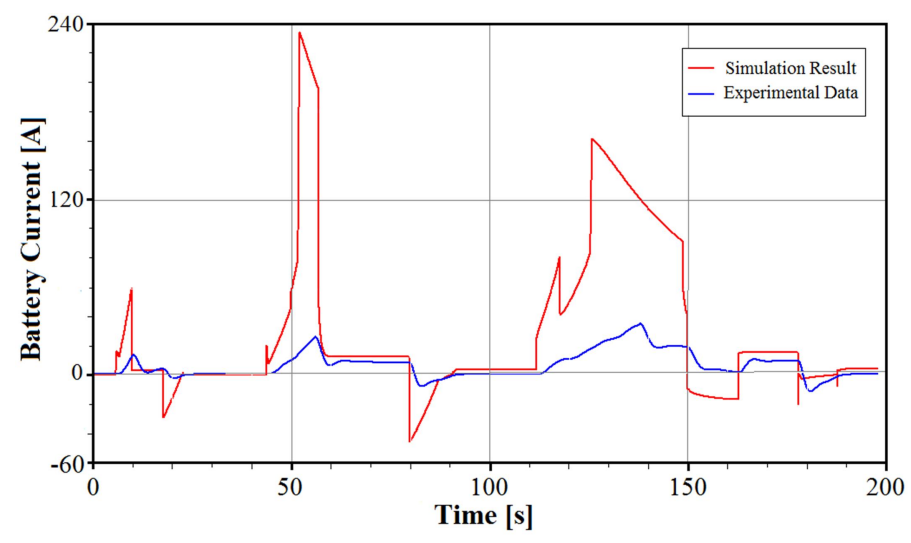

Fig. 6. First comparison between the reference data and the simulation results of the battery pack current.

For the optimization study it was used the optimization tool of ModelCenter ${ }^{\circledR}$. Once an objective function and the variable parameters are defined in this tool, it is able to find the best set of the variables which can minimize or maximize the objective function.

As optimization algorithm, it was chosen the "NSGA IINon-dominated Sorting Genetic Algorithm II', which is capable of doing a multi-objective analysis and providing a set of solutions to the user.

As objective functions were inserted two functions which calculate the errors between the real and the simulation curves of the Battery current and voltage, equations (14) and (15). 


$$
\begin{gathered}
E_{V}=\int_{t_{0}}^{t_{c y c l e}}\left(V_{S I M}-V_{R E A L}\right) d t \\
E_{C}=\int_{t_{0}}^{t_{c y c l e}}\left(I_{S I M}-I_{R E A L}\right) d t
\end{gathered}
$$

As shown in the equations (14) and (15) all the punctual errors of each iteration are taken into account and then summed, in order to give the global error of the simulation as a result.

The main characteristic of the chosen optimization algorithm is that it does not require to specify a weight for each objective function. Therefore, the curves of errors for the battery voltage and current are evaluated on the same level of importance.

Finally, once $R_{G}, \varphi_{F}$ and $R_{B}$ are defined as input parameters, ModelCenter ${ }^{\circledR}$ is able to run simulations on Dymola and read, at the same time, the values of the objective functions $\left(E_{V}\right.$ and $\left.E_{C}\right)$ for each simulation.

After performing about 667 simulations, the algorithm NSGA II detected the best configuration of parameters for the $477^{\text {th }}$ one, whose values are presented on Table 1 .

TABLE 1. OPTIMIZATION RESULTS

\begin{tabular}{|c|c|c|c|c|}
\hline $\boldsymbol{R}_{\boldsymbol{G}}$ & $\boldsymbol{\varphi}_{\boldsymbol{F}}$ & $\boldsymbol{R}_{\boldsymbol{B}}$ & $\boldsymbol{E}_{\boldsymbol{V}}$ & $\boldsymbol{E}_{\boldsymbol{C}}$ \\
\hline 10.381 & 0.4887 & 0.1367 & 73.64 & 391 \\
\hline
\end{tabular}

The new comparison of the real curve to the simulation results, measured by the Dymola Power Sensor at the output of the Battery, after the use of ModelCenter $\AA$, is shown in Fig 7. Briefly, despite some local errors, the match between the peaks of Battery current and voltage corroborated the validity of the optimization study.

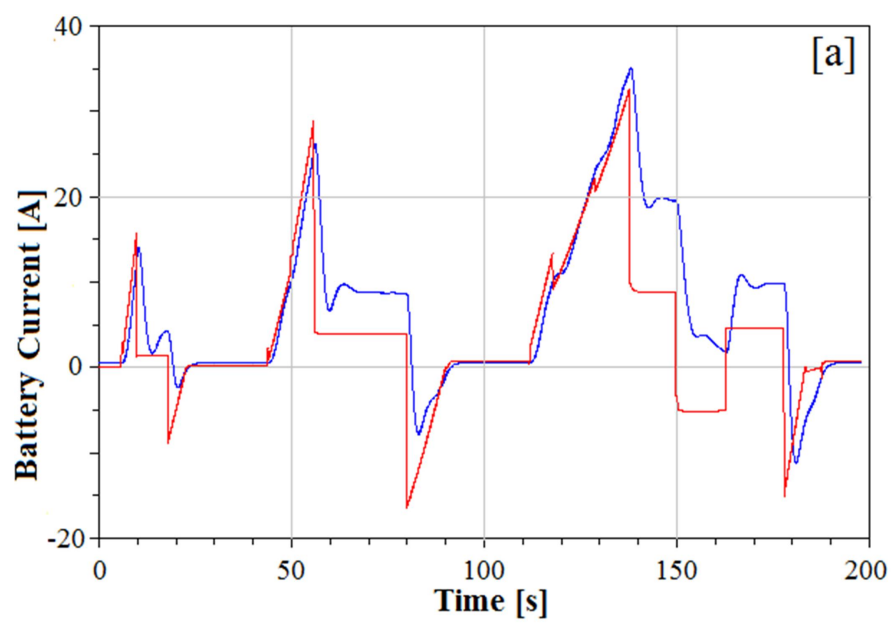

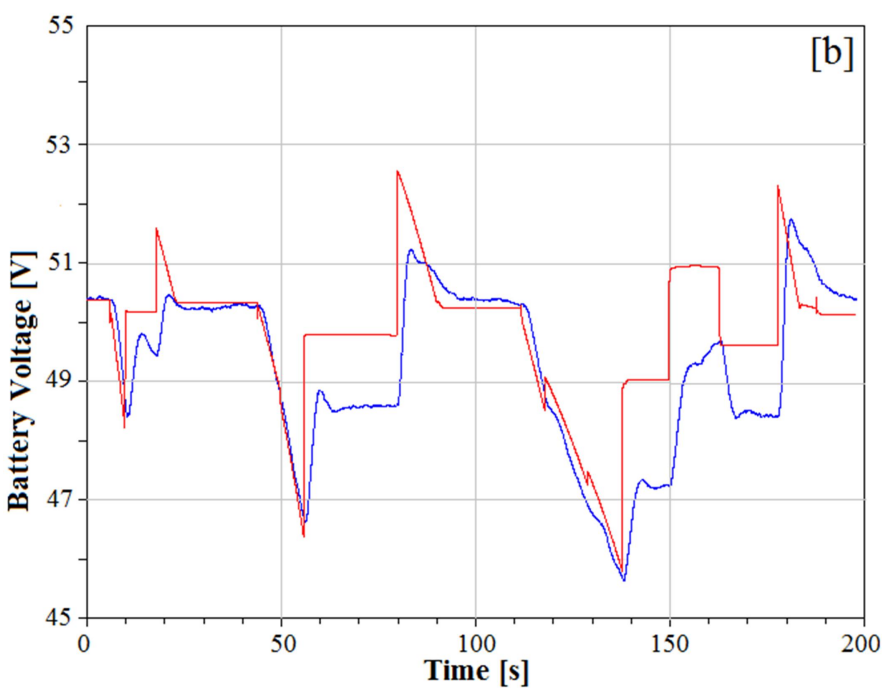

Fig. 7. Simulation (red) and real (blue) Battery Current[a] and Voltage [b] comparison.

\section{RESULTS}

After the validation process, the Dymola model of the scooter was used to calculate the energy required by an electric vehicle battery pack, whose project presents some specific driving-range requirements. It was assumed as range the distance that a vehicle can run using only one discharging cycle of the battery pack.

It is known that the value of energy required by the vehicle battery is fundamental for a designer of electric vehicles. As a matter of fact, its knowledge can provide an idea of the dimension and detailed performance characteristics of the battery pack. Thereby, for this study, the already created Dymola model was modified, as shown in Fig. 8.

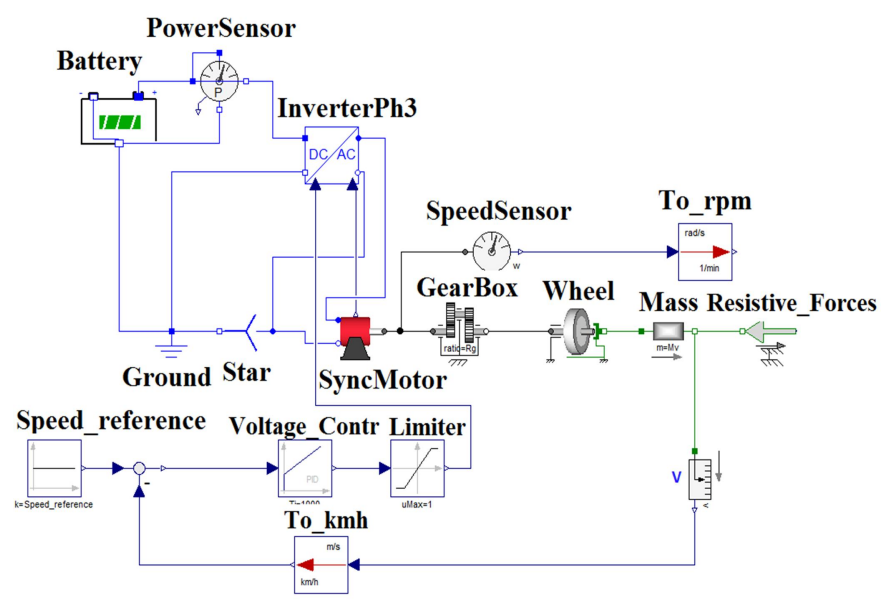

Fig. 8. Modified Dymola model

In order to calculate the energy required by the Battery pack, the Dymola model of power-train was modified. It was considered a constant speed reference for the control system and the brake was removed because its presence on the model 
would be useless. Further, in the power-train model, there were also inserted the following parameters:

- $W_{B}$ : it calculates the total energy in Wh used by the vehicle battery pack during the simulation;

$$
W_{B}=\frac{1}{360} \int_{0}^{t_{0}}{ }_{t_{0}}{ }^{M} P_{B} d t
$$

- $R_{V}$ : it estimates the range in $\mathrm{km}$ reached by the vehicle during the simulation;

$$
R_{V}=\frac{1}{100} \int_{0}^{t_{S I M}} V_{v} d t
$$

- $W_{R}$ : it is the relative parameter of energy spent for the vehicle to run a certain distance, measured in W.h/ $\mathrm{km}$.

$$
W_{R}=\frac{W_{B}}{R_{V}}
$$

For this study, another ModelCenter ${ }^{\circledR}$ tool, called "Parametric Study", was used.

The parametric study was initialized inserting the battery pack number of cells and the constant speed reference as input parameters, and $W_{R}$ as the output function.

In this way, once the number of cells is fixed, the software calculates the energy $W_{R}$ gradually modifying the value of speed reference between a minimum $(10 \mathrm{~km} / \mathrm{h})$ and a maximum value $(45 \mathrm{~km} / \mathrm{h})$.

The results of this study applied to the Scooter are shown on the graphic presented on Fig. 9. With these curves, it is possible to calculate the total energy required by the Scooter to run a specific range fixing the number of battery cells and its speed.

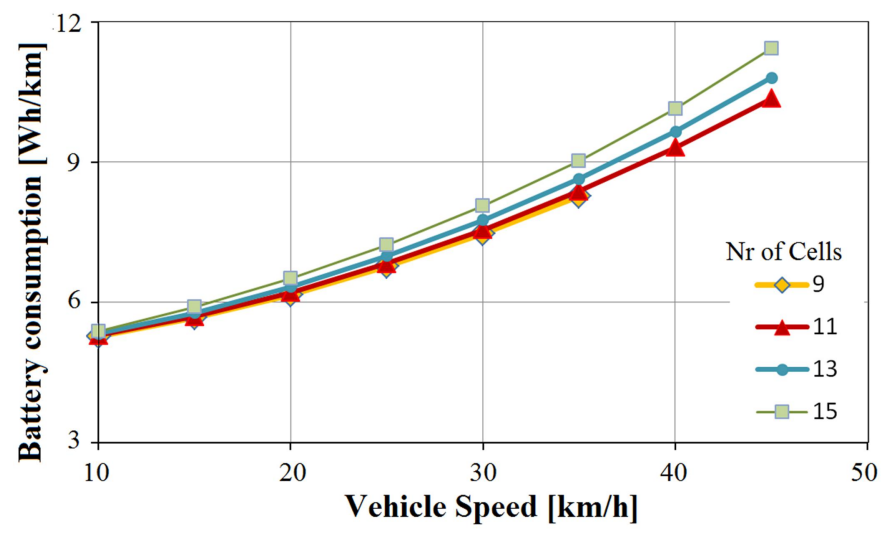

Fig. 9. Results of the parametric study

The calculated Battery consumption, for different numbers of battery cells and different constant values of the vehicle speed, are reported in Table 2.
TABLE 2. CALCULATED BATTERY CONSUMPTION

\begin{tabular}{|c|c|c|c|c|}
\hline \multirow{2}{*}{$\begin{array}{c}\text { Vehicle } \\
\text { Speed } \\
{[\mathbf{k m} / \mathbf{h}]}\end{array}$} & \multicolumn{4}{|c|}{ Number of Battery Cells } \\
\cline { 2 - 5 } & $\mathbf{9}$ & $\mathbf{1 1}$ & $\mathbf{1 3}$ & $\mathbf{1 5}$ \\
\hline 10 & 5,26 & 5,29 & 5,33 & 5,38 \\
\hline 15 & 5,66 & 5,69 & 5,77 & 5,89 \\
\hline 20 & 6,17 & 6,21 & 6,33 & 6,50 \\
\hline 25 & 6,77 & 6,83 & 6,99 & 7,22 \\
\hline 30 & 7,47 & 7,55 & 7,76 & 8,06 \\
\hline 35 & 8,27 & 8,38 & 8,65 & 9,02 \\
\hline 40 & 8,93 & 9,31 & 9,65 & 10,13 \\
\hline 45 & & 10,36 & 10,81 & 11,42 \\
\hline
\end{tabular}

In order to use the graphic above, first the designer has to enter through the $\mathrm{x}$-axis using the value of the vehicle speed required by his project, after that, he is able, choosing the number of the battery cells, to check on the y-axis the energy consumption $\left(W_{R}\right)$ of the designed electric propulsion system.

The total internal energy of the battery pack $W_{\text {TOTAL }}$ can be estimated using the equation (19), that takes in consideration one discharging cycle:

$$
W_{T O T A L}=\kappa W_{R} R_{D}
$$

where $\kappa$, is defined by:

$$
\kappa=\frac{1}{\left(S O C_{0}-S O C_{M I N}\right)}
$$

It is a factor that amplifies the value of the useful energy, so that it can be taken into consideration that the battery should be recharged when the value of SOC reaches a minimum threshold.

\section{CONCLUSIONS}

The design and development of a complex system, such as power-train, is a complex task that needs to be divided into several phases and be managed through an approach typical of Systems Engineering. This manuscript deals with the preliminary design phase of a propulsion system for an electric scooter. A model-based design approach is used to estimate vehicle performance and energy consumption for the considered propulsion systems.

The approach explained in the present manuscript represents a useful computational instrument which is expected to help engineers in the design of electric vehicles. Besides that, the created Dymola model, used with this approach, is very flexible because it can be changed and adapted to the characteristics of its components (battery pack, inverter, electric motor, control system, gear box, etc.) and parameters of electric vehicles (wheels, mass, frontal area, etc.) under study. The used models allow the simple testing of 
different system configurations thanks to their described modularity. Using these tools in the preliminary design phases of system engineering is useful to designers for different reasons: finding a configuration that is more suitable for a certain application; making a preliminary sizing of components, but also exclude a priori solutions that result to be unsuitable by the simulation.

It can be also concluded that the performed co-simulation between Dymola and ModelCenter ${ }^{\circledR}$, carried out in this paper, is able to improve the precision and the quality of the simulation results. Regarding to this aspect, the optimization tool has played an essential role on the improvement of the model, completing the small imperfections and limitations of the modeling environment of Dymola.

About the specific battery consumption results, presented in the last section of this paper, it is important to note that the parametric study, obtained using Model Center, enables a detailed designing of a battery pack for the electric vehicle under study. As a matter of fact, in this case, this tool has provided specific data about the battery back performance and physical characteristics, once the requirements of the project in question are fixed.

\section{ACKNOWLEDGMENT}

We wish to express our sincere thanks, to Mr. Antoine Brunner and Ms. Ymeng Dong, tutors of the PLACIS project at the Supméca Institut, for all their support and patience to obtain the results of this paper. We would like to acknowledge the technician of Istituto Motori, Mr. Antonio Rossi, for his cooperation during the experimental activities necessary to validate the models described in this manuscript.

\section{REFERENCES}

[1] Chu, Steven, and Arun Majumdar. "Opportunities and challenges for a sustainable energy future." nature 488.7411 (2012): 294-303.

[2] A. G. Boulanger, A. C. Chu, S. Maxx and D. L. Waltz, "Vehicle electrification: status and issues," Proceedings of the IEEE, vol. 99, no. 6, pp. 1116-1138, 2011.

[3] M. Alexander and M. Davis, "Total Cost of Ownership Model for Current Plug-in Electric Vehicles," 2013.

[4] M. Hammadi, J.-Y. Choley, O. Pen and A. Riviere, "Multidisciplinary approach for modelling and optimization of Road Electric Vehicles in conceptual design level," in "Electrical Systems for Aircraft, Railway and Ship Propulsion" (ESARS), 2012, 2012.

[5] Kossiakoff, Alexander, et al. "Systems engineering principles and practice". Vol. 83. John Wiley \& Sons, 2011.

[6] C. Zheng, M. Bricogne, J. Le Duigou and B. Eynard, "Survey on mechatronic engineering: A focus on design methods and product models," Advanced Engineering Informatics, vol. 28, no. 3, pp. 241-257, 2014.

[7] 3DS Academy - "Introduction to Systems Engineering - Discover RFLP method", 2012.

[8] Kleiner, Sven, and Christoph Kramer. "Model based design with systems engineering based on RFLP using V6." Smart Product Engineering. Springer Berlin Heidelberg, 2013. 93-102.

[9] Clemente Capasso, Ottorino Veneri, "Experimental Analysis on the Performance of Lithium Based Batteries for Road Full Electric and Hybrid Vehicles", Applied Energy, Volume 136, 31 December 2014, Pages $921 \quad-\quad 930, \quad$ ISSN $0306 \quad-\quad 2619$, http://dx.doi.org/10.1016/j.apenergy.2014.04.013.
[10] M. Einhorn, F. Conte, C. Kral, C. Niklas, H. Popp e J. Fleig, "A modelica library for simulation of elecric energy storages," in Proceedings of the 8th International Modelica Conference, 2011.

[11] Geoff Klempner, Isidor Kerszenbaum, "Handbook of Large TurboGenerator Operation and Maintenance", Chapter 1. Principles of Operation of Synchronous Machines, pp 3-31,2008 